\title{
PRECISAMOS FALAR SOBRE CURRÍCULO
}

\section{WE NEED TO TALK ABOUT CURRICULUM}

\section{Márden de Pádua Ribeiro'}

\begin{abstract}
Resumo: $O$ presente artigo tem por objetivo estabelecer uma reflexão teórica introdutória sobre o campo curricular. Destina-se especialmente para iniciantes que procuram por abordagens introdutórias, mas que não sejam rasas e superficiais. Possui como foco uma discussão inicial e atualizada, que visa estimular interessados na teoria curricular a se aprofundarem cada vez mais neste complexo e polissêmico campo da educação. Para isso, procura problematizar as vertentes tradicionais, críticas e póscríticas do currículo chamando atenção para seus limites potencialidades a partir da idéia de híbridos teóricos, ancorando-se em Alice Casimiro Lopes e Antônio Flávio Barbosa Moreira. Defende a temática do conhecimento como fundamental para o campo curricular e sua apropriação por distintas concepções de currículo. $\mathrm{O}$ artigo espera contribuir para preencher uma lacuna no que tange a disponibilidade de textos de caráter introdutório ao currículo com linguagem mais acessível para estudantes de graduação, professores da educação básica e interessados em geral. Trata de um trabalho teórico a partir de revisão bibliográfica interpretativa.
\end{abstract}

Palavras-chave: Currículo. Conhecimento. Cultura. Teorias.

\section{INTRODUÇÃO}

O intuito deste artigo é escrever sobre Currículo na educação. É falar de Currículo tendo como foco estudantes de graduação de Pedagogia. Futuros profissionais da educação que estão tendo contato pela primeira vez com este campo (Bourdieu, 1983) tão polissêmico, complexo, e recheado de híbridas concepções teóricas. O objetivo aqui, portanto é escrever sobre Currículo em um viés introdutório, pensando naqueles textos iniciais que o docente da disciplina de Currículo pretende trabalhar com seus alunos. É escrever sobre currículo de forma simples, mas não rasa, focando nos estudantes que lerão esse texto, como todos os outros de uma graduação, na corrida e dura luta do cotidiano; no transporte público, entre um intervalo e outro, dentro de suas casas nem sempre silenciosas e com todas as interrupções possíveis e imagináveis que possam desconcentrar uma leitura de um artigo.

Não significa dizer que esse texto tem um objetivo prosaico, muito pelo contrário. Simplificar um assunto é desafio árduo e que exige de quem o faz um conhecimento aprofundado. Só se simplifica o que se domina. Não há como construímos exemplos triviais e corriqueiros de assuntos que não façamos a menor idéia. Em outras palavras, penso esse artigo para estudantes de graduação, professores da

\footnotetext{
${ }^{1}$ Doutorando em Educação - PUCMG Mestre em Educação - PUCMG Professor do curso de Pedagogia - FACISABH.
} E-mail: <mardendepadua@yahoo.com.br>. 
educação básica que não estão plenamente inseridos nos áridos debates acadêmicos e que clamam por leituras de caráter introdutório e acessível.

Uma leitura introdutória é aquela que convida ao aprofundamento futuro. É aquela que visa ser didática, explicativa, propositiva, sem cair nos clichês, sem se render ao senso comum, sem perder o embasamento teórico. Uma leitura introdutória é fundamental no contexto dos cursos de graduação, especialmente de Pedagogia, foco do presente trabalho.

Em minha atividade profissional, leciono a disciplina de Currículo para um curso de Pedagogia. Tal informação traduz a preocupação desse artigo: possibilitar aos estudantes uma leitura convidativa e explicativa sobre currículo, com nítido caráter introdutório, abrindo as portas profundas e plurais do campo para quem deseja se aprofundar.

Em sua dissertação de mestrado, Ribeiro (2016) investigou como se dão as disciplinas de Currículo dos cursos de Pedagogia presenciais de Belo Horizonte e constatou que há uma lacuna da qual o presente artigo visa preencher: a sistematização de textos de caráter introdutório para graduandos de Pedagogia. Tal lacuna foi observada nas entrevistas que o autor realizou com os docentes das disciplinas de Currículo. A maioria deles trouxe tal demanda e é nela que me agarro para produzir esse texto.

Ribeiro (2016) constatou que basicamente todos os docentes de Currículo entrevistados utilizam introdutoriamente a clássica obra de Tomaz Tadeu Silva, Documentos de Identidade. Uma introdução às teorias de currículo, especialmente a introdução do livro, intitulada: Teorias de Currículo: o que é isto? Trata de uma curta e didática introdução que apresenta um breve histórico do campo curricular, enfatiza a importância de alguns conceitos e fornece uma notícia das três vertentes teóricas que Silva (2009) imortalizou: tradicionais, críticas e pós-críticas. É usual nos cursos de graduação que os docentes de Currículo trabalhem a partir dessas três vertentes e utilizem para fins didáticos o famoso quadro teórico elaborado por Silva (2009).

Não é intenção aqui substituir a introdução elaborada por Silva (2009) e sim, fornecer mais alternativas bibliográficas com caráter introdutório para estudantes interessados no tema do currículo. Para isso o presente trabalho é uma reflexão teórica, a partir de revisão bibliográfica interpretativa (Gil, 2002), que consistiu em um levantamento da produção no campo curricular que se relacionasse ao objetivo aqui pretendido. A partir disto, fiz uma interpretação da bibliografia levantada de modo a problematizar algumas questões que entendo ser relevantes ao público alvo deste artigo: estudantes de licenciaturas e interessados na discussão curricular em nível introdutório.

Desse modo, divido o texto em dois principais momentos: uma discussão problematizadora acerca das vertentes elaboradas por Silva (2009) a partir da ideia de híbridos teóricos (Lopes, 2005, 2007, 2013; Moreira, 1990, 1998, 2001, 2009, 2010) e a importância do tema do conhecimento e da cultura para o currículo. É evidente que um texto com esse objetivo está longe de querer abarcar toda a multiplicidade conceitual existente na academia, que faz do currículo seguramente um dos campos mais complexos, plurais e de difícil definição.

A complexidade do campo curricular nos últimos anos tem sido de tal ordem que cada vez mais é difícil definir, por exemplo, as fronteiras entre as concepções crítica e pós-crítica que Silva (2009) criou. As influências, no campo do currículo, dos estudos do cotidiano (Ferraço e Carvalho, 2012; Oliveira, 2013; Alves, 2003); da filosofia da diferença (Corazza, 2001; 2005, 2010); das políticas de currículo na perspectiva de Stephen Ball e Ernesto Laclau (Dias e Lopes, 2009; Lopes e Macedo, 2011); se embaralham com as concepções de currículo rizomático (Gallo, 2010); de currículo como vetor-força (Paraíso, 2015); currículo como espaço-tempo de enunciação cultural (Macedo, 2006); currículo como teia de significados (Pereira, 2012); do currículo atrelado à necessidade de transmissão do conhecimento poderoso (Young, 2007,2011,2013) e tantas outras. Mistura-se ainda às discussões específicas de gênero, etnia, tecnologia, que demandam do campo curricular ressignificações teóricas constantes.

Quem quer se enveredar pelo campo do currículo acaba de ter uma breve noção do amplo cardápio disponível. E o cardápio não está completo. Mas nossa intenção é introduzir e como tal, começar do início, do básico, daquilo que se precisa saber para as primeiras aulas de uma graduação. 
Também não é nossa intenção aqui fazer apanhados históricos do campo curricular. Entendo que para isso os docentes de Currículo podem e devem trabalhar com os estudos de Moreira (1990) e Goodson (1995).

A dissertação de Assunção (2012) e especialmente de Ribeiro (2016) são pontos de partida importantes na medida em que se dedicaram especificamente às disciplinas de Currículo dos cursos de Pedagogia, respectivamente em São Paulo e Belo Horizonte, pesquisando tanto em instituições públicas quanto privadas, ambas entrevistando docentes de Currículo. Acredito, portanto, que as duas pesquisas fornecem elementos significativos para uma compreensão mais clara dos desafios de se lecionar e de se aprender sobre currículo no contexto da graduação em Pedagogia.

Assunção (2012) em sua pesquisa trabalhou com planos de ensino das disciplinas de currículo de maneira mais superficial, estabelecendo um compilado das bibliografias mais utilizadas e das características mais comuns das disciplinas: carga horária, objetivos e em qual período se situam. Contudo, conseguiu pesquisar mais planos de ensino do que Ribeiro (2016), que por sua vez tratou as disciplinas de Currículo de modo mais profundo, pois entrevistou todos os docentes das respectivas disciplinas, ao passo que Assunção entrevistou apenas alguns, por amostra e não aprofundou a respeito dos desafios cotidianos dos docentes que lecionam a disciplina.

Assim, é possível elencar pontos em comum percebidos nas duas dissertações: o já referido livro de Tomaz Tadeu Silva é o mais citado nos planos de ensino e costuma ser escolhido para iniciar a disciplina inserindo os estudantes na lógica elaborada por Silva (2009) de enquadrar as vertentes teóricas do currículo entre tradicionais, críticas e pós-críticas. Ribeiro (2016) demonstrou que os docentes de Currículo por ele entrevistados, compreendem as categorias elaboradas por Silva (2009) como cruciais para um bom entendimento inicial sobre currículo por parte de seus estudantes.

É por essa razão que dou especial importância a essa obra de Tomaz Tadeu. Ora, se a intenção desse artigo é servir de texto introdutório especialmente para licenciaturas, e se trago pesquisas que mostram que sua obra tem servido de baliza teórica para o ensino de currículo, nada mais coerente do que destacar a divisão classicamente estabelecida por Silva (2009). Contudo, creio que apenas descrevê-la didaticamente não traz nenhuma relevância ao campo, pois para tal, a própria obra do referido autor já cumpre o papel. Nesse sentido, acolho as categorias tradicionais, críticas e pós-críticas de Silva (2009) no intuito de problematizá-las, ou seja, levantar discussões e estimular o debate e a ressignificação delas. Creio que desse modo, contribuo de forma mais efetiva para um debate mais produtivo acerca da teoria curricular, tendo em vista que essa discussão tem sido a meu ver, feita de forma tímida no campo curricular atualmente. Destaco os trabalhos da pesquisadora Alice Casimiro Lopes como fontes principais para quem busca um outro olhar acerca desses enquadramentos teóricos.

Retomando às dissertações de Assunção (2012) e Ribeiro (2016), outra conclusão possível de ambas as pesquisas trata da observação feita por alguns docentes de Currículo de que são escassos os textos introdutórios sobre Currículo. Além da obra de Silva (2009), alguns docentes buscaram a introdução do livro Teorias de Currículo de Alice Casimiro Lopes e Elizabeth Macedo como uma tentativa de alternativa ao livro de Silva (2009), mas alegaram que os discentes sentem dificuldade em interpretálos. A carência de textos de caráter introdutório, a partir de linguagem mais simples, é premissa central deste artigo.

Geralmente, em uma primeira aula sobre Currículo, após apresentarmos o plano de ensino e estabelecer as demais formalidades que toda primeira aula pede, os docentes iniciam suas discussões provocativamente com uma pergunta: afinal, o que é currículo? A estratégia aqui é clara: pinçar noções prévias de seus alunos e ao mesmo tempo iniciar um canal dialógico com eles a respeito do que venha a ser o currículo. Nesse momento o docente já sabe que ao mesmo tempo preparou uma armadilha para si, pois responder o que é currículo, atualmente trata de um desafio imenso ao campo.

Para teóricos como Moreira e Garcia (2003) atualmente o campo do currículo no Brasil encontrase disperso, ou seja, seu objeto central (o conhecimento) se dispersou a partir da contribuição de múltiplas vertentes teóricas. Os autores defendem que o currículo não deve se afastar de sua matéria 
prima: o conhecimento. Moreira $(2001,2003,2007,2010,2012)$ volta a defender essa questão em outros trabalhos, seguido por Ribeiro (2015, 2016b) e Ribeiro e Zanardi (2016). A mesma defesa, ainda mais vigorosa, é feita por Duarte (2016). Gabriel (2013, 2015, 2016), ainda que sob perspectiva teórica dos autores anteriormente mencionados, concorda com eles no que diz respeito à centralidade da temática do conhecimento para o campo curricular.

Por outra via, influenciados por teorias pós-modernas e pós-estruturais, outros teóricos compreendem o currículo mais como uma enunciação discursiva, enfatizando a diferença, como percebido nos trabalhos de Corazza $(2001,2005,2010)$ e de Paraíso (2009, 2010, 2015).

Vale ressaltar que há heterogeneidade em meio a essas concepções discursivas, pois fatalmente os pesquisadores que articulam currículo e cotidiano (Inês Barbosa de Oliveira; Nilda Alves; Carlos Eduardo Ferraço) possuem nuances diferentes daqueles que priorizam as políticas de currículo, como Lopes $(2015,2014,2013)$ e Macedo $(2013,2012,2006)$.

Portanto, não é tarefa simples definir currículo, pois como os teóricos adeptos de uma lógica mais discursiva diriam, defini-lo é antes de tudo travar uma batalha discursiva pelas múltiplas significações possíveis do que venha a sê-lo. Por isso existem diferentes concepções teóricas que darão respostas distintas para o currículo e suas ênfases.

Sugiro aqui um ponto de partida conceitual que pode ser útil para quem quer iniciar os estudos no campo: compreender a temática do conhecimento como fundamental para o currículo. Seja para defender a transmissão dos ditos conhecimentos historicamente acumulados pela humanidade (Duarte, 2016; Young, 2007, 2011, 2013), seja para pensar o conhecimento na ótica discursiva, através de disputas por diferentes enunciados (Gabriel, 2016, 2015, 2013), seja para pensar o conhecimento como diluído em uma temática maior: a da cultura (Lopes, 2013), seja para defender o conhecimento como matéria prima central para o currículo (Moreira, 2003, 2007, 2010, 2012; Ribeiro, 2016b, Ribeiro e Zanardi, 2015). O conhecimento pode ser pensado sob múltiplas formas mais uma coisa é elementar: não há como desconsiderá-lo quando o assunto é currículo.

Por essa razão o conhecimento é uma espécie de matéria prima dos estudos de currículo. Ele é a base essencial para a teoria curricular. Dele, emergem-se outras diversas temáticas. Do mesmo modo que com a madeira, você pode fazer uma mesa, um armário, uma cadeira, ou um piano. A madeira é a matéria prima, ela é o elemento primordial que fornecerá as múltiplas potencialidades de criação a partir do objeto.

Em uma aula de graduação, geralmente no início do semestre, costumo provocar os alunos a partir de uma situação hipotética: peço para que se imaginem em uma sala de aula, lecionando o componente curricular História para o quinto ano do ensino fundamental. Deparam-se com a intencionalidade de se trabalhar o conteúdo do descobrimento do Brasil com os alunos do quinto ano, certamente contido no livro didático.

Reflito então com os estudantes que o próprio termo descobrimento que geralmente é uma escolha curricular de diversos livros didáticos de História, já trazem embutidas visões de mundo (européia nesse caso) que explicam, por exemplo, o motivo pelo qual o termo não seria invasão. Via discurso, podemos compreender essa questão partir do modo pelo qual diferentes significantes travam duelos discursivos pelo enunciado. Em outro sentido, pode-se problematizar porque o conhecimento tido como historicamente construído privilegiou o termo descobrimento em detrimento de invasão. Em outras palavras, tal problematização significa recorrer à consagrada pergunta estabelecida por Apple (2006) ao se estudar currículo: conhecimentos de quem? Construídos e legitimados por quem? Tais questões remetem os alunos às noções de disputa, poder, ideologia que tanto a teoria crítica curricular tem mencionado nas últimas décadas. Mas também pode ser acrescida de toda a lógica discursiva, via linguagem, que as teorias pós-críticas têm procurado ressaltar.

E é nesse contexto que Silva (2009) ainda é central, pois sua divisão esquemática que categoria as teorias curriculares em três grandes vertentes, ainda auxilia introdutoriamente estudantes a se situarem dentro desse complexo campo. Entretanto gestada há quase duas décadas, esta divisão merece um bom debate acerca de seus sentidos no atual polissêmico campo curricular. 


\section{AS TEORIAS TRADICIONAIS, CRÍTICAS E PÓS-CRÍTICAS DE TOMAZ TADEU SILVA E OS DESAFIOS DE PENSÁ-LAS ATUALMENTE.}

Como já mencionado, a divisão esquemática do campo curricular nessas três vertentes, têm sido usual no contexto dos cursos de graduação em Pedagogia. Não é minha intenção aqui simplesmente fazer um resumo dessas três vertentes, pois entendo que para isso já existe o próprio livro de Tomaz Tadeu Silva. Creio que a contribuição desse artigo pode ser, a partir desse enquadramento elaborado por Silva (2009), convidar os interessados no campo curricular a pensar o conhecimento a partir dessas três vertentes, e por fim, estimular a problematização de tais categorias, a partir de uma certa mistura entre essas vertentes (hibridismo teórico), para que não sejam compreendidas de modo tão separado e rígido.

Em outras palavras, pretendo estimular quem está começando a se aventurar pelo campo, a perceber as teorias tradicionais, críticas e pós-críticas, não como etapas evolutivas, no sentido de que primeiro vem uma, depois outra e outra, como se a teoria de currículo fosse um elevador em que cada andar corresponde a uma teoria melhor do que a outra. Ao contrário, gostaria que elas fossem pensadas de forma misturada, ou na perspectiva de Lopes (2005, 2007, 2014, 2013) e Moreira (1990, 2001, 2009, 2010), hibridizadas. Isso significa, especialmente entre as teorias críticas e pós-críticas, que muito mais do que uma oposição, elas possuem pontos de encontro como ressalta Ribeiro (2016b) e mesmo com suas distinções, não se trata de uma anular a outra. Elas podem ser entendidas como vertentes que se hibridizam em diversos pontos e talvez essa seja o desafio mais importante para os interessados no campo curricular.

As teorias tradicionais para Silva (2009), datadas historicamente especialmente a partir das contribuições de Ralph Tyler na década de 1930, possuem como marca principal a tentativa de enfatizar o planejamento curricular sem maiores preocupações com a problematização a respeito do conhecimento. Esta concepção busca associar na educação os princípios de administração científica tayloristas marcados por uma lógica industrial. Esse modelo instrumental não se preocupa com maiores reflexões críticas e

muito menos com questionamentos acerca de quais conhecimentos são selecionados/excluídos.

O que é fundamental que estudante de graduação que estejam navegando inicialmente pelo campo do currículo percebam, em relação às teorias tradicionais? Não se pode negar a importância do estabelecimento de planejamentos e objetivos de ensino para um professor. Não significa que um professor ao traçar seus cronogramas de conteúdos, está aderindo a uma lógica tradicional, de caráter nitidamente tecnicista. Isso ocorre se tais sistematizações se dão por parte do docente sem um mínimo de reflexão crítica sobre sua prática, tentando atingir uma ilusória neutralidade no ato de selecionar os conhecimentos que os alunos devem aprender. Ao buscar problematizar, criticar, refletir e revelar o caráter ideológico presente nos conhecimentos, esse docente se aproxima das outras duas vertentes categorizadas por Silva (2009): críticas e pós-críticas. Silva (2009, p.30) sintetiza, de um modo geral, a concepção crítica curricular nesta passagem:

as teorias críticas sobre o currículo começam por colocar em questão precisamente os pressupostos dos presentes arranjos sociais e educacionais. As teorias críticas desconfiam do status quo, responsabilizando-o pelas desigualdades e injustiças sociais. As teorias críticas são teorias de desconfiança, questionamento e transformação radical. Para as teorias críticas o importante não é desenvolver técnicas de como fazer o currículo, mas desenvolver conceitos que nos permitam compreender o que o currículo faz.

O autor, após tecer tal síntese, busca diferir a teoria crítica, havendo de um lado uma teorização mais geral, amparada nas obras de Louis Althusser, Bourdieu e Passeron, e de outro, teorizações críticas mais voltadas ao currículo, calcadas na chamada Nova Sociologia da Educação, encabeçada por Michael Young, e no neomarxismo de Michael Apple, além do movimento de reconceptualização, liderado por Willian Pinnar. Silva (2009) após perpassar por esses autores em sua obra, enfatiza uma questão central 
a uma teorização crítica: a necessidade de articulação com a temática do conhecimento. Assim, chama especial atenção para a contribuição de Michael Apple que, para Silva (2009), possui uma concepção essencialmente crítica, ao direcionar seus questionamentos às relações de poder e como a assimetria dessas relações afetam o currículo, além da importância do conhecimento para discutir tais relações.

As teorias pós-críticas, no entendimento de Silva (2009) são fruto de diversas correntes teóricas e buscam atribuir ênfases distintas das teorias críticas. Buscam trazer à tona outros elementos (gênero, discurso, etnia, sexualidade,) que as teorias críticas não procuraram enfatizar em seus primórdios. Paraíso (2004, p. 285) resume em duas elucidativas passagens, as premissas básicas das concepções pós-críticas:

Usando uma linguagem que recebe influências da chamada "filosofia da diferença", do pós-estruturalismo, do pós-modernismo, da teoria queer, dos estudos feministas e de gênero, dos estudos multiculturalistas, póscolonialistas, étnicos, ecológicos etc., as teorias pós-críticas realizam, no campo educacional brasileiro, substituições, rupturas e mudanças de ênfases em relação às pesquisas críticas. Suas produções e invenções têm pensado práticas educacionais, currículos e pedagogias que apontam para a abertura, a transgressão, a subversão, a multiplicação de sentidos e para a diferença.

As pesquisas pós-críticas em educação no Brasil explicitam aquilo que não constitui objeto de seus interesses: não gostam de explicações universais, nem de totalidades, nem de completudes ou plenitudes. Em vez disso, optam claramente por explicações e narrativas parciais, pelo local e pelo particular (Silva, 1993a). Não se preocupam com comprovações daquilo que já foi sistematizado na educação, nem com "revelações" ou "descobertas". Preferem a invenção, a criação, o artefato, a produção (Corazza, 2001). Não acreditam na "suposta" autonomia do sujeito ou da subjetividade, à qual nós da educação não cansávamos de apegar-nos. Consideram o sujeito um efeito da linguagem, dos textos, do discurso, da história, dos processos de subjetivação (Silva, 1999). [...] Tais pesquisas têm problematizado as promessas modernas de liberdade, conscientização, justiça, cidadania e democracia, tão difundidas pelas pedagogias críticas brasileiras, abdicado da exclusividade da categoria classe social e discutido, também, questões de gênero, etnia, raça, sexualidade, idade (Louro, 1995). (Paraíso, 2004, p.285-286)

Sintetizando as duas vertentes, pode-se dizer que as diferenças se dão especialmente nas ênfases conceituais que ambas priorizam. Enquanto a teoria crítica acolhe noções mais totalizantes, tais como: ideologia, hegemonia, transformação, emancipação, razão; as teorias pós-críticas têm optado por ressaltar percepções que desconfiam da totalidade, da racionalidade, da universalidade, para tal, têm buscado operar com conceitos de diferença, discurso, enunciação, desejo. Essas concepções têm influenciado bastante os estudos que se voltam, especialmente para a articulação do currículo com a cultura, currículo com o gênero e a sexualidade.

Para Lopes (2013, p.13), a noção de teorias pós-críticas é algo complicado, pois "trata-se de uma expressão vaga e imprecisa que tenta dar conta de um conjunto de teorias que problematizam esse cenário pós-moderno". Segundo a autora, esse conjunto de teorias inclui os estudos pós-estruturais, pós-coloniais, pós-modernos e pós-marxistas. Ribeiro (2016b) acolhe em grande parte essa premissa e acrescenta que dentro das teorias pós-críticas há uma corrente adjetivada pelo autor como radical, que para ele corresponde a uma influência extrema das teorias filosóficas pós-estruturais que acabam por deixar o campo curricular por demais abstrato. Mas há outras correntes pós-críticas que buscam hibridizar seus conceitos com fundamentos da teoria crítica, buscando mais um encontro do que um afastamento.

É importante trazermos, para melhor elucidação, o famoso quadro elaborado por Silva (2009) tão abordado nos cursos de graduação: 
Quadro 1 - Categorias curriculares elaboradas por Tomaz Tadeu Silva

\begin{tabular}{|l|l|l|}
\hline Teorias Tradicionais & Teorias Críticas & Teorias pós-críticas \\
\hline Ensino & Ideologia & Identidade, alteridade, diferença \\
\hline Aprendizagem & Reprodução cultural e social & Subjetividade \\
\hline Avaliação & Poder & Significação e discurso \\
\hline Metodologia & Classe social & Saber-poder \\
\hline Didática & Capitalismo & Representação \\
\hline Organização & Relações sociais de produção & Cultura \\
\hline Planejamento & Currículo oculto & Gênero, raça, etnia, sexualidade \\
\hline Eficiência & Emancipação e libertação & Multiculturalismo \\
\hline
\end{tabular}

Fonte: (Silva, 2009, p.17).

Tal quadro, reproduzido aqui em parte, vale dizer, foi elaborado pelo autor há quase duas décadas, o que significa dizer que ele é fruto da produção curricular específica daquele contexto no Brasil e no mundo. Por essa razão, vale a pena, mesmo nesse texto introdutório, que os interessados pelo campo curricular, tenham conhecimento de tais distinções, mas sem perder de vista um questionamento: tais distinções ainda fazem total sentido no contexto da produção curricular atual? Defendo que em parte sim, mas não totalmente, pois com o passar dos anos, especialmente a teoria curricular crítica passou a absorver contribuições das teorias chamadas pós-críticas, ocorrendo aí uma hibridização teórica (Lopes, 2014, 2013), observada também por Moreira (, 2010, p.61) ao afirmar que "a hibridização enquanto categoria propicia uma visão mais acurada da conformação do campo do currículo no Brasil".

Lopes e Macedo (2002) também defendem a ocorrência de uma hibridização e argumentam que as marcas do campo são a mescla entre os discursos crítico e pós-crítico. Assim, há uma "reterritorialização de discursos filosóficos e sociológicos, que tornam mais difusa a constituição de uma teoria do currículo" (Lopes e Macedo, 2002, p. 48). Vale ressaltar que o termo hibridização tem sido aplicado aos difusos fenômenos culturais contemporâneos. Contudo, segundo Moreira (1990, 2009, 2010) o próprio termo currículo pode ser analisado como híbrido se o concebermos como resultado de uma seleção de parcela da cultura mais ampla disponível e de sua transformação, para que possa ser ensinada, em um dado momento, em uma instituição específica, para um alunado particular. Em outras palavras, trata-se de hibridizações nos quais discursos de origens distintas e hierarquizados de diferentes modos se desterritorializam e reterritorializam. "Os discursos curriculares também podem ser estudados como híbridos, por corresponderem a configurações transitórias que resultam de diferentes tradições e movimentos pedagógicos" (MOREIRA, 2010, p.61). Em outro trabalho, o autor complementa:

A hibridização opera, então, por meio da mobilização de distintos discursos em um âmbito particular. Articula tanto modelos externos, por vezes repetindo movimentos tradicionais do centro para a periferia, quanto diferentes tradições e teorizações. A hibridização supõe um processo de tradução, que coloca novas experiências e direções em contato com outras previamente disponíveis. Interrompem-se, no processo, as hierarquias estabelecidas dos discursos, sem que, necessariamente, se configure uma outra, mais democrática. Na nova hierarquia, reafirmam-se e sancionam-se alguns discursos, ao mesmo tempo que se negligenciam e reprimem outros. (MOREIRA, 2009, p.372)

A análise desses discursos demanda entendê-los não só como decorrentes de disputas entre correntes, mas também como manifestações de conflitos não resolvidos. Falar em hibridização teórica no campo do currículo não necessariamente significa defender que haja uma harmonia entre distintas 
concepções teóricas. Elas ao se hibridizarem, negociam seus sentidos, se reterritorializam sob disputas, e se ressignificam a partir de discursos que acabam se sobrepondo em detrimento da restrição de outros. É sempre importante indagar: no processo de hibridismo teórico, que temáticas são privilegiadas? "Que vozes se revelam mais poderosas?” (MOREIRA, 2009, p.373) Sob quais condições as disputas por hegemonia no campo se dão e como interferem na produção desses conhecimentos? Por essa razão, o hibridismo no campo, ao mesmo tempo em que desestabiliza a concepção linear de tradições teóricas, embaralhando distintas vertentes, por outro lado, colocam ainda mais sob disputa quais discursos acabam enfatizados e quais outros são diluídos ou até mesmo negligenciados

Especialmente os trabalhos de Giroux $(1993,1997)$ e McLaren $(1993,1997)$ já há muito tempo se pautam pela hibridização entre vertentes críticas e pós-críticas. Em entrevista para o periódico Currículo sem Fronteiras, o teórico Michael Apple expressou claramente que tem buscado hibridizar Karl Marx (concepção crítica) com as assertivas de Foucault (concepção pós-crítica), como pode ser observado em Gandin, Silva e Marques (2012).

Silva (2009), ao lançar sua clássica obra destinada à introdução da teoria curricular, certamente prestou grande contribuição didática, ao separar críticos de pós-críticos, elencando categorias conceituais que ambas correntes priorizam. Essas categorias estabelecidas por Silva (1999), por um lado, ajudam a compreender essas singularidades conceituais da teoria curricular, mas por outro, podem acarretar em uma estagnação das concepções, caso lidas de modo estanque, desconsiderando que teorias críticas ou pós-críticas, também continuam em constantes transformações, além do fato de não serem homogêneas em si mesmas.

Em outras palavras o que quero dizer é que caso não se tenha um devido cuidado, pode ser que se acabe interpretando que determinado conceito que está colocado no quadro como pertencente à vertente crítica, só possa ser trabalhado pela mesma. Um exemplo: Silva (2009) ao elaborar seu enquadramento das teorias, colocou a cultura no campo das teorias pós-críticas. Caso seja feito uma leitura rígida desse quadro, dá-se a entender então que as teorias críticas não operam com o conceito de cultura, o que seria um equívoco.

A pesquisa feita por Ribeiro (2016) com docentes de Currículo de cursos de Pedagogia revela exatamente o que quero aqui mencionar. $O$ pesquisador ao coletar as falas dos docentes, mostrou que em diversos momentos, os mesmos revelam que seus estudantes acolhem uma visão compartimentada do quadro teórico de Silva (2009) e também evolutiva, isto é, compreendem que das teorias tradicionais, para as críticas e pós-críticas há uma espécie de linha de evolução. Sei que a noção estanque e rígida do quadro não são defesas que Silva (2009) faz em seu livro; o que quero dizer aqui diz respeito aos perigos que decorrem de determinadas leituras de sua obra.

Entretanto, no que diz respeito à noção de linha evolutiva entre as correntes, creio que cabe problematizar um pouco mais a obra de Silva (2009). Ainda que não haja uma intencionalidade explícita do autor em traçar uma linha evolutiva das correntes curriculares, o autor acaba advogando por uma delas ao mencionar que "o pós-modernismo assinala o fim da pedagogia crítica e o começo da pedagogia pós-crítica". (Silva, 2009, p.116). Considero tal frase emblemática. Ao determinar o fim de uma vertente e o começo de outra, não estaria Silva (2009) aderindo indiretamente a uma concepção evolutiva das correntes? Ou, no mínimo, a uma compreensão linear, de que uma termina para a outra começar?

Assim, não é difícil entender porque, na pesquisa de Ribeiro (2016) com os docentes de Currículo, os mesmos observaram o problema da interpretação linear e evolutiva das correntes categorizadas por Silva (2009). Tais compreensões dificultam o que aqui procuro estimular: a busca pelos encontros das fronteiras em detrimento do apressamento em demarcá-las como polos opostos. Lopes (2013) sintetiza com precisão a forma cronológica e linear de como se tem construído a teoria curricular, sobretudo em alguns cursos de graduação.

No campo do currículo, a expressão teorias pós-críticas é utilizada para se referir às teorias que questionam os pressupostos das teorias críticas, marcadas pelas influências do marxismo, da Escola de Frankfurt e em alguma 
medida da fenomenologia, discussões em que as conexões entre currículo, poder e ideologia são destacadas. Nessa perspectiva, por vezes estabelece-se uma linha do tempo na história do pensamento curricular, como se o currículo tivesse evoluído das teorias tradicionais para as teorias críticas de enfoque moderno e estruturalista para em seguida avançar para as teorias pós-críticas. Em cursos de graduação, é muito comum construirmos esse gradualismo linear para a história do currículo, mesmo quando afirmamos opor-nos a ele. (Lopes, 2013, p.11).

Conforme Lopes (2013) aponta, ao apostarmos no gradualismo, tem-se a ideia de uma etapa social que necessariamente irá evoluir para um momento mais avançado em relação à etapa atual, sugerindo uma linearidade ilusória. A meu ver, a frase anteriormente citada de Silva (2009) decretando o fim de uma corrente e o início de outra, escorrega exatamente nessa precipitação ilusória.

É nesse sentido que apostamos na categorização dos híbridos teóricos, no intuito de captar os deslizamentos entre vertentes curriculares que misturam muito mais do que separam. Estes híbridos teóricos congregam elementos crítico e pós-críticos, dificultando um enquadramento mais estático que sugere categorias críticas de um lado e pós-críticas de outro, ou a morte de uma e o nascimento de outra.

Entretanto, algumas distinções contidas no quadro ainda permanecem bastante perceptíveis ao campo e isso deve ser deixado claro nas licenciaturas e para os interessados em iniciar as leituras sobre currículo. A principal delas a meu ver trata da ênfase da idéia de discurso para as teorias pós-críticas. Certamente essa foi uma contribuição pós-crítica cuja teoria crítica pouco se debruça, pois está mais interessada em uma dimensão mais concreta da realidade, sob uma perspectiva materialista e menos discursiva. Outra boa distinção ainda muito presente que o quadro acolhe, é a importância do conceito de emancipação para a teoria crítica. Silva $(2000,2010)$ em outros trabalhos, deixa claro que a idéia de emancipação para os pós-críticos é bastante questionada, ao defenderem que o sujeito, mergulhado no discurso, não é assim tão dotado de uma racionalidade emancipatória. Por outro lado, teóricos críticos como Giroux (1993, 1997), McLaren (1993, 1997), Moreira (2001, 2003, 2009, 2010, 2012) e Duarte (2016) ainda que concordem que a razão não possui total plenitude no sujeito, por outro lado não abandonam a capacidade racional de libertação e emancipação da qual o sujeito pode conquistar.

Vale dizer, a título de maior esclarecimento, que usualmente se busca alinhar teorias críticas e pós-críticas com dois grandes paradigmas teóricos: Modernidade e Pós-modernidade, respectivamente. Peters (2000) esclarece com precisão as distinções e as heterogeneidades presentes nesses dois paradigmas, de modo que aqui nos cabe resumi-los através de duas grandes diferenças: enquanto a Modernidade, majoritariamente, trabalha com uma visão estrutural de sociedade, acolhendo a idéia de totalidade, de se pensar a sociedade na perspectiva macro, e defendendo alguns valores tidos como universais, a Pós-modernidade enfatiza a realidade através de uma perspectiva discursiva, priorizando o local e o particular em detrimento da idéia de total e universal. Assim, a razão para a Modernidade é um valor central, enquanto para a Pós-modernidade é um princípio visto com bastante desconfiança. Em outras palavras, usualmente, a partir de Silva $(2000,2009,2010)$ se enxerga a teoria crítica como uma espécie de defensora dos paradigmas da Modernidade, e a teoria pós-crítica como adepta da Pósmodernidade.

No entanto, como já dito, tal distinção se entendida rigidamente, torna-se problemática, pois desconsidera justamente os hibridismos teóricos que embaralham teoria crítica e pós-crítica. Para Silva (2009, p.115) o pós-modernismo, raiz teórica das concepções pós-críticas, "de certa forma, constitui uma radicalização dos questionamentos lançados às formas dominantes de conhecimento pela pedagogia crítica". Essa radicalização resulta, para o autor, na eliminação de "qualquer pretensão de emancipação". Tal premissa é algo com o qual os teóricos como Lopes (2014, 2013), Giroux (1993), Ribeiro (2016b), Ribeiro, Zanardi e Veloso (2016) e Moreira (2001, 2003, 2007, 2010, 2012) não concordam. Estes teóricos defendem um diálogo entre críticos e pós-críticos, ressaltando o que os segundos têm a oferecer aos primeiros. É como se estes autores deslizassem (Macedo, 2012) entre 
teorias críticas e pós-críticas, absorvendo suas contribuições, dificultando de modo considerável a demarcação dessas fronteiras, por se tratarem de híbridos teóricos.

A sugestão para as licenciaturas é tentar perceber os deslizamentos ocorridos entre ambas as concepções. O leitor pode retomar àquele quadro elaborado por Silva (2009) e debater os seguintes questionamentos: os conceitos relacionados às teorias pós-críticas, passadas quase duas décadas, seguem aqueles mesmos ou outros podem ser acrescentados ao quadro? Conceitos como desejo, central nos trabalhos de Paraíso (2009, 2010, 2015); diferença, crucial nos estudos de Corazza (2001, 2005, 2010), e tantos outros, comuns nos trabalhos de orientação pós-crítica, tais como: rizoma, cartografia, multiplicidade, vitalismo curricular; se fôssemos atualizar o quadro de Silva (2009) tais conceitos não fariam mais sentido, do que, por exemplo, multiculturalismo; identidade; representação, um trio conceitual bastante questionado nos trabalhos atuais de linhagem pós-crítica?

Isso é apenas um exemplo, e ao mesmo tempo uma sugestão, de como aproveitar o quadro de Silva (2009) não para ser seguido literalmente, mas, ao contrário, para servir como parâmetro para sua própria ressignificação e problematização. Seria especialmente desafiador e rico em termos de aprendizado, um debate nas licenciaturas, das potencialidades e limites do quadro de Silva (2009) no campo atual da produção curricular brasileira.

O que significa deslizar entre teoria crítica e pós-crítica? Do ponto de vista de Scocuglia (1999, p.175) é transitar pela representação e apresentação da própria realidade, é não abdicar da totalidade, mas não ignorar a diferença, "[...] o surpreendente, o instintivo, o sentimento, as escolhas individuais, os fragmentos". Porém, isso não implica, no que o autor denomina como "ingenuidade em negar as grandes estruturas" (Scocuglia, 1999, p.177). Vale a pena observar, a título de exemplo, como o curriculista Antônio Flávio Barbosa Moreira é compreendido como um autor que a todo momento passeia por entre distintas concepções:

a dificuldade de situar o pensamento de Moreira entre as tradições crítica e pós-estruturais não ocorre apenas em relação à temática do conhecimento, mas é nela que adquire um tom mais dramático. Em diferentes trabalhos, o autor argumenta em favor das utopias modernas para a escola, definindo-se como um teórico crítico. Sua descrição da contemporaneidade, no entanto, se dá no quadro das preocupações manifestadas pelo pensamento pós-crítico. Questões em torno da cultura, da fragmentação identitária, do relativismo do conhecimento surgem mescladas com a aposta nessas utopias. Há um deslizamento entre uma descrição que leva em conta os desafios da teoria póscrítica e a crença em um projeto moderno de superação da crise da sociedade atual. (Macedo, 2012, p.726).

Problematizar esses enquadramentos é fundamental para evitar as estagnações e os rótulos, caso contrário, por exemplo, a cultura será monopólio da vertente pós-crítica, pois lá está colocada no enquadramento do lado pós-crítico. No entanto, a cultura é tema crucial também aos críticos, seja como política cultural (Giroux, 1997), seja como vinculada ao conhecimento escolar, (Moreira, 2001, 2003, 2007, 2010, 2012) seja no âmbito da hegemonia (Apple, 2006). Do mesmo modo, a classe social, colocada como categoria crítica, hoje é relativizada pelos próprios teóricos críticos, que entendem tal categoria como importante, mas que sozinha não pode explicar todas as dinâmicas sociais (Apple, Au, 2011).

A teoria crítica senão ressalta a diferença como a pós-crítica, não a anula ao abarcar a totalidade, nem compreende a classe social como o único componente de explicação das relações sociais. Apple e Au (2011) ao tomarem o neomarxismo como base de análise, chamaram atenção para a insuficiência, nos dias atuais, do conceito de classe para explicar toda a dinâmica social e também para a importância de não desdobrar as análises sobre as relações sociais em um economicismo ortodoxo. Nesse sentido, já não faria sentido então a retirada do conceito classe social como um atributo tipicamente crítico?

Algo parecido ocorre com o conceito de identidade, colocado no enquadramento de Silva (2009) como um atributo pós-crítico, mas hoje em dia os próprios estudos dessa natureza tecem duras críticas 
à idéia de identidade, privilegiando o conceito de diferença (Lopes, 2015, 2014, 2013); Macedo (2013, 2012, 2006); Paraíso (2004, 2009, 2015). Nesse sentido, é emblemático o artigo do próprio Tomaz Tadeu Silva, que tece duras críticas à noção de identidade e advoga pelo conceito de diferença (SILVA, 2002). O mesmo Tomaz Tadeu que na década de 90 escreveu sua obra Documentos de Identidade. Ou seja, o tempo faz com o que o campo curricular se ressignifique, o que não significa que o enquadramento de Silva (2009) deve ser desconsiderado, mas problematizado no âmbito da formação de professores.

Não se quer aqui defender a teoria crítica e a pós-crítica como sinônimas. Existem diferenças de ênfases em algumas categorias e rupturas mais claras em relação a algumas questões. Defendemos também que uma não anula a outra, não decreta o fim da outra, muito menos que uma não pode dialogar com a outra. Reiteramos a possibilidade de diálogo entre as duas vertentes que pode se dar no limite de suas fronteiras. Justamente no acolhimento, por parte das teorias críticas, de problematizações típicas da corrente pós-crítica, mas que não chegam a tirar das teorias críticas sua utopia e sua defesa por projetos de sociedade. De outro modo, as teorias críticas que acolhem acepções pós-críticas compreendem que os projetos de sociedade que defendem não se constituem na verdade sacralizada e sim em um ponto de vista, propositivo e discursivo, que, para além do discurso e do texto em si, visa uma intervenção em determinadas realidades, visando ressignificá-las.

Onde então reside a fronteira entre críticos e pós-críticos? Problematizar tais correntes críticas e pós-críticas é se permitir misturá-las, acolhendo seus "insights" (Giroux, 1997), enxergar suas ênfases. Trata-se de colocá-las em disputa, como é o campo curricular, mas não no sentido de uma que mata a outra, mas no sentido de atuar na fronteira entre ambas, na tênue demarcação (provisória e contingencial) que as difere.

De certo modo, ninguém é somente crítico ou pós-crítico. Tais discursos podem e devem se imbricar, ainda que com limites de fronteira, embora frágeis. Na luta por uma sociedade melhor talvez ambos se encontrem, seja do ponto de vista discursivo-textual ou do ponto de vista da ação concreta na realidade material.

\section{AS DISTINTAS CATEGORIAS E SUA RELAÇÃO COM A TEMÁTICA DO CONHECIMENTO}

Para professores da educação básica que por ventura lerem esse texto e para futuros profissionais da educação, uma pergunta se impõe: o que os alunos devem aprender/saber? A pergunta é simples, mas a resposta é complexa, conflituosa, plural e para algumas vertentes teóricas, impossível de ser respondida, enquanto para outras, deve ser respondida, nem que para isso se travem duras batalhas em busca de algum tipo de consenso possível. Vale a pena esse debate no âmbito da graduação e no cotidiano da escola básica, ainda mais em contextos de Base Nacional Comum Curricular. Será que se perguntarmos a todos os professores de língua portuguesa de uma escola, todos falarão a mesma coisa? Será que não haverá nenhum consenso possível?

Possivelmente, professores de matemática não discordarão que é essencial e básico que seus alunos saiam dos primeiros anos do ensino fundamental ao menos sabendo as quatro operações matemáticas. Há como discordar? Da mesma forma os professores de língua portuguesa esperarão que os pedagogos que lecionem nos anos iniciais do fundamental consigam entregar alunos que ao menos escrevam o próprio nome, para os anos finais. Então, existem alguns consensos básicos, triviais e até óbvios? Supostamente sim. Mas e para além dessa questão?

Até porque, para além do um mais um da matemática, pode-se discutir, por exemplo, sob que perspectiva os problemas matemáticos se constroem. Em outras palavras, há docentes que privilegiam na construção dos problemas, uma lógica cooperativa calcada na idéia da distribuição igualitária e socialização de objetos. Para isso, utilizam dos conteúdos da fração, das quatro operações, dos percentuais, da geometria, inserindo-os na resolução de problemas que sirvam a uma lógica cooperativa. Outros docentes sequer percebem essas potencialidades, e investem em problemas matemáticos que operam com princípios do acúmulo (quanto João ganhou e quanto José perdeu?), da competição e do individualismo. Ou seja, até nas ciências exatas, a questão ideológica do conhecimento se faz presente. 
E se indagarmos por quais motivos nas aulas de História alguns conhecimentos recebem especial atenção enquanto outros desaparecem? A história do Oriente, do continente africano, as culturas nativas, as mulheres, o campo, todos eles, muitas vezes coadjuvantes da História nas salas de aula, enquanto grandes heróis não-problematizados, grandes civilizações ocidentais, ganham imenso destaque. Os portugueses afinal são conquistadores/desbravadores ou invasores? Por que não trazer esse debate para os alunos da escola básica, ao invés de fornecermos o significado fechado? Na graduação, cabe especialmente à disciplina de Currículo fornecer essa reflexão a respeito da importância da temática do conhecimento.

Como debater a questão agrária na Geografia? Discutir a terra a partir de quais visões, interesses e concepções? E a questão ambiental? Do mesmo modo, nas aulas de ciências, a própria noção de corpo humano, por si só, pode e deve ser problematizada para além do conhecimento acerca das funções dos sistemas (algo que também é fundamental). O que é um corpo? Os corpos são iguais? Os corpos nutridos e subnutridos são os mesmos? Os corpos não possuem nenhuma relação com classes sociais? Tais exemplos demonstram como uma noção de currículo problematizadora, acarreta em uma prática docente que instigará os alunos da educação básica a refletir sobre aquele conhecimento, e não somente absorvê-lo sob uma ilusória neutralidade.

Moreira e Candau (2008) chamam a atenção para o movimento de recontextualização que o conhecimento passa para se tornar escolarizado. Em outras palavras os autores concebem o conhecimento escolar como uma construção específica do âmbito educativo e não como uma mera simplificação de conhecimentos produzidos fora da escola. Reiteram ainda que o conhecimento escolar tem características próprias que o distinguem de outras formas de conhecimento.

Desse modo, os conhecimentos ensinados na escola não são cópias exatas de conhecimentos socialmente construídos. "Assim, não há como inserir, nas salas de aula e nas escolas, os saberes e as práticas tal como funcionam em seus contextos de origem." (Moreira e Candau, 2008, p.26). Para se tornarem conhecimentos escolares, os conhecimentos de referência sofrem uma descontextualização e, a seguir, um processo de recontextualização. Em outras palavras, o conhecimento socialmente construído acerca da Revolução Francesa, ou da Teoria da Relatividade, que chega ao contexto do ensino superior, são primeiramente descontextualizados para se recontextualizarem na lógica escolar, especialmente na educação básica.

Assim, a temática do conhecimento escolar é importante para o currículo, pois ao indagarmos de quem são os conhecimentos que estão em jogo nas escolas, refletimos automaticamente quais são também suas exclusões e recontextualizações. O docente ciente dessa questão compreende a não neutralidade desse processo, e realiza suas escolhas de forma muito mais consciente de sua responsabilidade enorme perante a seleção dos conhecimentos. Tudo isso carrega como pano de fundo sempre aquela clássica questão: o que meus alunos devem saber? Procuro em minhas aulas iniciais sempre metaforizar essa questão a partir de um prosaico problema: imagine que você quer fazer uma viagem para a praia nas férias, em seu carro, e está pensando em quem levará contigo. Família, amigos; certamente não caberão todos em seu veículo e escolhas precisarão ser feitas. Decidir o que entra e o que sai dirá decisivamente do objetivo que você pretende na viagem. Grosso modo, essa é a lógica das escolhas dos conhecimentos na educação.

Tal questão se relaciona diretamente com um determinado perfil de aluno que almejamos contribuir para formar. Assim, implicitamente há outra pergunta: o que meus alunos devem ser? É evidente que o saber não se dá apenas no âmbito da sala de aula, muito menos a formação dos sujeitos como um todo. Mas a escola pode e deve se inserir como mais uma das possibilidades de construção do sujeito, e, sobretudo, deve propiciá-lo ir além de onde ele já está, como salienta Moreira e Candau (2008). Ir além é abrir aos alunos o máximo possível de horizontes e isso implica em desvelar o mundo com esses alunos e não para eles, refletindo junto deles o caráter ideológico presente nos conhecimentos escolares (Apple, 2006; Freire, 2013).

Debater com os alunos se é descobrimento ou invasão do Brasil, estimulá-los a refletir por que os livros didáticos de História dão imenso destaque para a Europa e tímido para a Ásia, refletir por que as leis de Newton são bem mais enfatizadas que a teoria da relatividade de Einstein ou a Física Quântica, 
problematizar as noções de língua certa e errada; tudo isso significa exercer um tipo de educação problematizadora que certamente nem a teoria curricular crítica nem a pós-crítica irão discordar num primeiro momento.

Ao pensarem sob o viés do conhecimento, teoria crítica e pós-crítica curricular certamente irão enfatizar nuances diferentes. O descobrimento/invasão do Brasil no viés crítico possivelmente ganhará uma análise mais voltada para as relações históricas que permitem com que determinados grupos sociais legitimem seus conhecimentos e silenciem outros e que isso não está desarticulado de todo um modo de produção econômico capitalista que contribui para determinar essas instâncias do conhecimento.

Por sua vez, teorias pós-críticas, cada uma a seu modo, verão na questão discursiva uma esfera crucial para debater o binômio discursivo descobrimento/invasão do Brasil, salientando que as questões de poder se inserem na linguagem, via discurso, e que conflitar essas duas terminologias é se inserir na disputa travada por significados, que é antes de tudo, também uma questão de saber-poder.

É importante, a título de introdução aos estudos curriculares, que estudantes de graduação, professores da educação básica e/ou interessados em geral, percebam que discutir conhecimento também é discutir cultura na medida em que se inserem nos conhecimentos, visões e concepções de mundo, bem como projetos de sociedade. Tudo isso está ali embutido nas escolhas diárias que os docentes fazem com seus alunos, muitas vezes sem se dar conta da seriedade desse processo. Tal conscientização da importância dessas reflexões nos faz acreditar que o docente não será um mero repetidor dos currículos dos sistemas educacionais e do livro didático adotado nas escolas. Também não quero dizer que ele irá sonegá-los, negligenciá-los. Ele pode ser um problematizador de tais documentos.

O conhecimento, nesse sentido, é componente que possibilita o encontro entre vertentes distintas no campo curricular. Vale trazer aqui as perguntas fundamentais feitas por Giroux (1997), que todo docente que se interessa pelo campo curricular pode e deve se fazer a cada momento que refletir sua prática:

1. O que conta como conhecimento curricular?

2. Como tal conhecimento é produzido?

3. Como tal conhecimento é transmitido em sala de aula?

4. Que tipos de relacionamentos sociais em sala de aula servem para espelhar e reproduzir os valores e normas incorporados nas relações sociais aceitas de outros lugares sociais dominantes?

5. Quem tem acesso a formas legítimas de conhecimento?

6. Aos interesses de quem este conhecimento está a serviço?

7. Como são mediadas as contradições e tensões políticas e sociais através de formas aceitáveis de conhecimento escolar e relacionamentos sociais?

8. Como os métodos de avaliação predominantes servem para legitimar as formas de conhecimento existentes? (Giroux, 1997, p.45)

Tais perguntas nos levam a questionar: de quem são esses conhecimentos, de quem são essas culturas, quais são os discursos em duelo por esse enunciado? Esse debate não pode ser negligenciado no âmbito da graduação, pois ele atende diretamente à realidade do docente em sala de aula.

\section{CONCLUSÕES}

Em um artigo que se pretende abertamente introdutório e convidativo ao campo do currículo, parece estranho falar em conclusão de um texto. Toda a idéia do presente do texto é de abertura. Abrir as cortinas do currículo para os primeiros minutos do espetáculo. O desejo é que esse texto possa ser um primeiro momento, uma porta de entrada, um subsídio para o docente de Currículo que deseje um texto nas aulas iniciais, um artigo que possa ser lido por interessados em geral em seus momentos de folga, de intervalo no trabalho, de deslocamento entre uma escola e outra, e nas férias, por que não? 
Este texto convida o leitor a ler mais sobre currículo. A se aprofundar mais ainda nessas teorias críticas e pós-críticas. Convida ainda para que o leitor possa mergulhar na diversidade existente dentro da própria teoria crítica, compreendendo-a como uma vertente que se aproxima e dialoga com contribuições pós-críticas/pós-modernas.

Estimula também ao leitor interessado, um mergulho no emaranhado de influências e variações das teorias pós-críticas, percebendo como algumas enfatizam o conceito de diferença e rizoma, através da influência de pensadores como Gilles Deleuze, Jacques Derrida e Félix Guattari, enquanto outras priorizam políticas de currículo no viés discursivo, sob influência de Stephen Ball e Ernesto Laclau, sem se esquecer dos estudos do cotidiano que se embasam fundamentalmente em Michel de Certeau.

Os leitores que decidirem se embrenhar pelo campo do currículo poderão perceber que existem encontros possíveis entre teorias críticas e pós-críticas, mas também há fronteiras. Irão se deparar com trabalhos que relacionam o currículo a uma infinidade de temáticas, desde as mais "clássicas" (conhecimento, cultura, identidade, diferença) até as mais "improváveis" (mídias, sustentabilidade, redes sociais, machismo, rizoma).

É fundamental que se perceba a importância do currículo como o coração da escola, mas que não se limite apenas às instituições formais. É crucial que o currículo seja problematizado e encarado como algo não neutro, ao contrário, como um componente que carrega em si mesmo, disputas ideológicas, discursivas, culturais. Quem estuda currículo com afinco, não leciona do mesmo modo, não se torna o mesmo professor como antes, não planeja da mesma maneira, nem avalia do mesmo jeito. Estudar o currículo transforma o docente, a equipe gestora e os profissionais da educação no geral.

Sim, são muitos nomes, vertentes teóricas e categorias conceituais. Muitos olhares, muitos discursos, muitas concepções. Isso assusta no começo, mas isso é bom. Significa que o interessado no campo curricular terá vasto cardápio para se alimentar e principalmente, misturar esses alimentos. Se levarmos a sério a educação, precisaremos falar de currículo.

\section{REFERÊNCIAS}

ALVES, Nilda. Cultura e Cotidiano Escolar. Revista Brasileira de Educação. n. 23, p.61-74, 2003.

ASSUNÇÃO, Alda Ribeiro Martins. A Inserção do Componente Currículo nos Cursos de Pedagogia do Estado de São Paulo. (Mestrado) Pontifícia Universidade Católica de São Paulo, 2012.

APPLE, Michael. Ideologia e Currículo. 3ed. Porto Alegre: Artmed, 2006.

APPLE, Michael. AU, Wayne. Repensando a reprodução: o neomarxismo na teoria da educação crítica. In: APPLE, Michael. AU, Wayne, GANDIN, Luís Armando. Educação crítica. Análise Internacional. Porto Alegre: Artmed, p. 100 -114, 2011.

BOURDIEU, Pierre. Questões de Sociologia. Rio de Janeiro: Marco Zero, 1983.

CORAZZA, Sandra. O Que quer um currículo? Petrópolis: Vozes, 2001.

CORAZZA, Sandra. Diferença pura de um pós-currículo. In LOPES, A. e MACEDO, E. (Orgs.). Currículo: debates contemporâneos. São Paulo: Cortez, p. 103-114, 2005.

CORAZZA, Sandra. Os sentidos do currículo. Revista Teias, v. 11, n. 22, p. 149-164, 2010.

DIAS, Rosanne Evangelista. LOPES, Alice Casimiro. Sentidos da prática nas políticas de currículo para a formação de professores. Currículo sem Fronteiras. v.9, n.2, p.79-99, 2009.

DUARTE, Newton. Os conteúdos escolares e a ressurreição dos mortos: contribuição à teoria históricocrítica do currículo. Campinas: Autores Associados, 2016.

FERRAÇO, Carlos Eduardo. CARVALHO, Janete Magalhães. Currículo, cotidiano e conversações. Revista e-curriculum. São Paulo, v.8 n.2, p.1-17, 2012.

FREIRE, Paulo. Pedagogia do oprimido. 33.ed. Rio de Janeiro: Paz e Terra, 2013.

GABRIEL. Carmen Teresa. Conhecimento científico e currículo: anotações sobre uma articulação impossível e necessária. Revista Teias, v. 14, n.33, p.44-57, 2013. 
GABRIEL, Carmen Teresa. Docência, demanda e conhecimento: articulações em tempo de crise. Curriculo Sem Fronteiras, v. 15, p. 425-444, 2015.

GABRIEL, Carmen Teresa. Conhecimento escolar e emancipação : uma leitura pós-fundacional. Cadernos de Pesquisa (Fundação Carlos Chagas. Impresso), v. 46, p. 104-130, 2016.

GALLO, Sílvio._ Educação: entre a subjetivação e a singularidade. Educação (UFSM), v. 35, p. 229-243, 2010.

GANDIN, Luís Armando.; SILVA, Maria Vieira.; MARQUES, Mara Rúbia Alves. Contradições e ambiguidades do currículo e das políticas educacionais contemporâneas - Entrevista com Michael Apple. Currículo sem Fronteiras, v.12, n.1, p. 175-184, 2012.

GIROUX, Henry. O Pós-Modernismo e o discurso da crítica educacional. In: SILVA, Tomaz Tadeu. (Org.). Teoria educacional crítica em tempos modernos. Porto Alegre: Artes Médicas, p.41-73, 1993.

GIROUX, Henri. Os professores como intelectuais: rumo a uma pedagogia crítica da aprendizagem. Porto Alegre: Artes Médicas, 1997.

GOODSON, Ivor. Currículo: teoria e história, Petrópolis: Vozes, 1995.

LOPES, Alice Ribeiro Casimiro. Política de Currículo: Recontextualização e Hibridismo. Currículo sem Fronteiras, v.5, n.2, p.50-64, 2005.

LOPES, Alice Casimiro. Currículo no debate modernidade, pós-modernidade. In: AMORIM, Antonio Carlos. Passagens entre moderno para o pós- moderno: ênfases e aspectos metodológicos das pesquisas sobre currículo. Campinas, SP: FE/UNICAMP, GT Currículo da ANPed, p. 16-21, 2007.

LOPES, Alice Ribeiro Casimiro. Teorias pós-críticas, política e currículo. Educação, Sociedade \& Culturas, $\mathrm{n}^{\circ} 39,2013$.

LOPES, Alice Casimiro. Mantendo o conhecimento na conversação curricular, porém via discurso: um diálogo com Gert Biesta. Rev. educ. PUC-Camp., Campinas, 19(2):99-104, 2014.

LOPES, Alice Casimiro. Por um currículo sem fundamentos. Linhas Críticas (UnB), v. 21, p. 445-466, 2015.

LOPES, Alice Ribeiro Casimiro; MACEDO, Elizabeth. O pensamento curricular no Brasil. In: LOPES, A. Casimiro; MACEDO, E. (Org.). Currículo: debates contemporâneos. São Paulo: Cortez, 2002.

LOPES, Alice Casimiro. MACEDO, Elizabeth. Contribuições de Stephen Ball para o estudo de Políticas de Currículo. Ball, Stephen; Mainardes, Jefferson (org). In: Políticas Educacionais: questões e dilemas. São Paulo: Cortez, 2011.

MACEDO, Elizabeth. Currículo como espaço-tempo de fronteira cultural. Revista Brasileira de Educação, v. 11, n. 32 , p. 285-296, 2006.

MACEDO, Elizabeth. Currículo e conhecimento: aproximações entre educação e ensino. Cadernos de Pesquisa, v.42 n.147 p.716-737, 2012.

Macedo, Elizabeth. A noção de crise e a legitimação de discursos curriculares. Currículo sem Fronteiras, v. 13, p. 436-450, 2013.

MCLAREN, Peter. Pós-Modernismo, Pós-Colonialismo e Pedagogia. In: SILVA, Tomaz Tadeu. (Org.). Teoria educacional crítica em tempos modernos. Porto Alegre: Artes Médicas, p.9-41, 1993.

MCLAREN, Peter. A vida nas escolas. Uma introdução á pedagogia crítica nos fundamentos da educação. 2ed. Porto Alegre: Artes Médicas, 1997.

MOREIRA, Antonio Flavio Barbosa.; GARCIA, Regina Leite. Currículo na contemporaneidade: incertezas e desafios. São Paulo: Cortez, 2003.

MOREIRA, Antônio Flávio Barbosa. Currículos e programas no Brasil. Campinas: Papirus, 1990. 
MOREIRA, Antônio Flávio Barbosa. O Campo do Currículo no Brasil: os anos noventa. Currículo sem Fronteiras, v.1, n.1, p.35-49, 2001.

MOREIRA, Antônio Flávio Barbosa (Org.). Currículo: questões atuais. 7ed. Campinas, SP: Papirus, 2003.

MOREIRA, Antônio Flávio Barbosa. A Importância do conhecimento escolar em propostas curriculares alternativas. Educação em Revista, Belo Horizonte, v. 45, p. 265-290, 2007.

MOREIRA, Antônio Flávio Barbosa. A configuração atual dos estudos curriculares: a crise da teoria crítica. In: PARAíSO, Marlucy. (Org.). Antonio Flavio Barbosa Moreira: pesquisador em currículo. Belo Horizonte: Autentica, p. 95-115, 2010.

MOREIRA, Antônio Flávio Barbosa. A produção de conhecimento na área de currículo e repercussões na qualidade da escola pública. XVI ENDIPE - Encontro Nacional de Didática e Práticas de Ensino UNICAMP - Campinas - 2012.

MOREIRA, Antônio Flávio Barbosa. CANDAU, Vera Maria. Currículo, conhecimento e cultura. In: Indagações sobre currículo. Brasília: Ministério da Educação, Secretaria de Educação Básica, p.17-34, 2008.

MOREIRA, Antônio Flávio Barbosa. Estudos de currículo. Avanços e desafios no processo de internacionalização. Cadernos de Pesquisa, São Paulo, v.39, n.137, 367-381. 2009.

OLIVEIRA, Inês Barbosa. Currículo e processos de aprendizagemensino: Políticaspráticas Educacionais Cotidianas. Currículo sem Fronteiras, v. 13, n. 3, p. 375-391, 2013.

PARAíso, Marlucy. Pesquisas pós-críticas em educação no Brasil: esboço de um mapa. Cadernos de Pesquisa, v. 34, n. 122, p. 283-303, 2004.

PARAÍSO, Marlucy Alves . Currículo, desejo e experiência. Educação e Realidade, v. 34, p. 277-293, n. 2009.

PARAÍSO, Marlucy Alves. Diferença no currículo. Cadernos de Pesquisa (Fundação Carlos Chagas. Impresso), v. v.40, p. 591-609, 2010.

PARAísO, Marlucy. Um currículo entre formas e forças. Educação (Porto Alegre), v. 38, n. 1, p. 49-58, 2015.

PEREIRA, Talita Vidal. Currículo como teia de significados. Revista Teias, v.12, n.27, p.161-176, 2012.

PETERS, Michael. Pós-estruturalismo e filosofia da diferença. Tradução: Tomaz Tadeu da Silva. Belo Horizonte: Autêntica, 2000.

RIBEIRO, Márden de Pádua . A pluralidade de concepções a respeito do currículo na perspectiva de professores de um curso de Pedagogia. Movimento Revista de Educação, v.2, n.2, p.1-28, 2015.

RIBEIRO, Márden de Pádua. O "currículo" na pedagogia: uma análise crítica da disciplina de Currículo nos cursos de Pedagogia. Dissertação (Mestrado)- Pontifícia Universidade Católica de Minas Gerais. Programa de Pós-Graduação em Educação. 289p. 2016.

RIBEIRO, Márden de Pádua. Teorias críticas e pós-críticas: pelo encontro em detrimento do radicalismo. Movimento Revista de Educação, v.3, n.5, p.1-34, 2016b.

RIBEIRO, Márden de Pádua.; ZANARDI, Teodoro Adriano Costa. Pela necessidade da articulação da temática do conhecimento nas disciplinas de currículo dos cursos de Pedagogia. Revista Tempos e Espaços em Educação, São Cristóvão, Sergipe, Brasil, v. 9, n. 20, p. 89-100, 2016.

RIBEIRO, Márden de Pádua.; ZANARDI, Teodoro Adriano Costa.; VELOSO, Silene Gelmini Araújo. Fim da teoria crítica? Crítica aos extremos pós-modernos e pós-estruturais da teoria curricular. Currículo sem Fronteiras, v. 16, n. 2, p. 255-282, 2016.

SCOCUGLIA, Afonso Celso. A História das Idéias de Paulo Freire e a atual crise de paradigmas. 2. ed. João Pessoa: Ed. Universitária / UFPB, 1999. 
SILVA, Tomaz Tadeu. Monstros, ciborgues e clones:os fantasmas da Pedagogia Crítica. In: SILVA, Tomaz Tadeu. Pedagogia dos monstros: Os prazeres e os perigos da confusão de fronteiras. Belo Horizonte: Autêntica, 2000.

SILVA, Tomaz Tadeu. Identidade e diferença: impertinências. Educação \& Sociedade, ano XXIII, no 79, p. 65-66, 2002.

SILVA, Tomaz Tadeu. Documentos de identidade: uma introdução às teorias do currículo. 3 ed. - Belo Horizonte: Autêntica, 2009.

SILVA, Tomaz Tadeu. 0 currículo como fetiche: a poética e a política do texto curricular. Belo Horizonte: Autêntica, 2010.

YOUNG, Michael. Para que servem as escolas? Educ. Soc., Campinas, vol. 28, n. 101, p. 1287-1302, 2007.

YOUNG, Michael. O futuro da educação em uma sociedade do conhecimento: o argumento radical em defesa de um currículo centrado em disciplinas. Revista Brasileira de Educação, v. 16 n. 48, 2011.

YOUNG, Michael. Superando a crise na teoria do currículo: uma abordagem baseada no conhecimento. Cadernos CENPEC, São Paulo, v.3, n.2, p.225-250, 2013. 